\title{
Future challenges of the impact agenda
}

Book or Report Section

Accepted Version

Setter, J. (2018) Future challenges of the impact agenda. In:

Mclntyre, D. and Price, H. (eds.) Applying Linguistics:

Language and the impact agenda. Routledge, London, pp.

179-184. ISBN 9781138237513 Available at

http://centaur.reading.ac.uk/77031/

It is advisable to refer to the publisher's version if you intend to cite from the work. See Guidance on citing.

Publisher: Routledge

All outputs in CentAUR are protected by Intellectual Property Rights law, including copyright law. Copyright and IPR is retained by the creators or other copyright holders. Terms and conditions for use of this material are defined in the End User Agreement.

www.reading.ac.uk/centaur 


\section{CentAUR}

Central Archive at the University of Reading

Reading's research outputs online 


\section{4}

\section{Future challenges of the impact agenda}

\section{Jane Setter}

In these days of accountability and government league tables, it's quite possible to feel like you're not much more than a bean, waiting to be counted. This is no less the case in UK academia and, increasingly, in academia elsewhere in the world. We are required to be accountable for the money we receive from the government, external funding agencies, and also from student fees (in countries where they apply). Where research funding is concerned, the person in the street might ask, very reasonably, what is the point of those academic experts and their research if not to contribute to society in an overt way? And shouldn't that contribution be demonstrable and quantifiable?

One could claim that publishing a journal article means the outcomes of research will filter down naturally and eventually to inform societal change as a whole. This may be true but, as the chapters in this volume have indicated, it may take a very long time for this to happen, have no observable trail by which it can be traced, and be very difficult to quantify, unless specific steps are taken from the outset to plan how to go about doing this. Even then, it's not always a straightforward task. In an environment where university funding is competitive, and universities are run - through necessity - more like large multinational companies than educational establishments of the "dreaming spires" variety, being able to demonstrate clearly how one's work has had "an effect on, change or benefit to the economy, society, culture, public policy or services, health, the environment or quality of life, beyond academia" 1 may not be the easiest thing to do ... but neither does it seem entirely unreasonable.

The collection of chapters in this book highlight some of the superb work being done by academics in linguistics as a subject area, how it is possible to be "impactful" in a REF sense (or by other countries' standards), and how to demonstrate that impact effectively, i.e., to report it in such a way that the benefit on those outside of academia is obvious and palpable. The authors

\footnotetext{
${ }^{1}$ http://impact.ref.ac.uk/CaseStudies/FAQ.aspx
} 
lay out why it is important for university research to add value outside of academia, how linguistics can contribute, and seem favourably disposed to the notion that it should. They also outline quite clearly the issues surrounding the impact agenda and how impact is counted, and raise a number of issues, including 1) that the use of this rude instrument fails to capture the value of some of the excellent public engagement work academics are doing because they simply don't fit into the metrics; and 2) that the current impact agenda could be subverting an academic's desire to research something purely for interest.

I came into academia more or less by accident from an English Language Teaching (ELT) background. As a teacher in private language schools, I had made use of books and other materials developed from research in applied linguistics based on theories and practice in second language acquisition, such as Krashen's input hypothesis (1985), Halliday’s systemic functional linguistics (1978) and Brumfit and Johnson's communicative approach (1979). These approaches, delivered through well-crafted materials, had been shown to have a positive impact on second language (L2) learning and, particularly, spoken communication in a way that old fashioned methods such as Grammar Translation had not. Applied linguistics, therefore, is eminently and demonstrably impactful. However, many of these approaches took a long time to result in teaching materials, let alone in good L2 learning outcomes, and I doubt very much whether the scholars involved were asked by their universities or government agencies to produce a report or case study showing exactly what their theories had achieved in the real world.

As is pointed out in the preceding chapters, the impact agenda in the UK kind of crept up on us unannounced; even though there may have been hints if you attended the right workshops, academics were not aware that they would have to show impact in the way defined by REF 2014 until the details were revealed. Demonstrating impact in applied linguistics research is going to be a piece of cake ... right? Not so. While I was aware that my work on Hong Kong English pronunciation and speech prosody among children with speech and language deficits could result in practical applications for global English communication and speech and language therapy (SLT) respectively, I had not been working on that research with the need to demonstrate actual impact of the kind described in REF 2014 in mind. The research team on the clinical projects had disseminated our findings in SLT newsletters and events, but we didn't have any evidence that practitioners had actually taken our findings on board and made changes in their practice. 
Another issue here, and one which is raised in this book, concerns (continued) funding to make impact activities possible. Grant applications arising from my Hong Kong English research, specifying awareness-raising and outreach sessions for English language teachers in Hong Kong and elsewhere in their impact statement, have failed to get funding, and so the potential for impact from that research has not been realised.

In fact, I have ended up in a very similar situation to that described by Lynne in Chapter 4; I do a lot of valuable awareness-raising public external engagement activity which looks like impact to my research lead, but none of it directly arises from my key research activities and so I cannot be entered as an impact case study in REF 2021. Public audiences are more interested in my forensic interests (in 2014, for example, I appeared on international broadcast media, advising where Jihadi John might come from based on his accent), issues to do with accents, accent prejudice and language change (I was interviewed for The Observer article which correctly attributed the Great Scone Map of the UK, described by David, Marie-José and Adrian in Chapter 8, to the University of Cambridge), and general issues to do with English language usage, such as the grocer's (grocers'?) apostrophe. As a co-editor of the Cambridge English Pronouncing Dictionary (Jones, 2011), I do frequently get asked to adjudicate or comment on "correct" pronunciation (how many of you are correctly pronouncing "Moët"? ${ }^{2}$ ), but that is also not linked directly to my research. For REF, it is not enough to be an expert and to be disseminating one's general expertise in a user-friendly, non-academic way; one has to be an expert who has either been in the opportune situation, as described in some chapters in this book, of having research which matched an external agenda and can be turned to it, or who has seen impact coming and planned accordingly, as suggested by Neil in Chapter 13.

Neil also points out that UK-based academics, at least, will not be caught short by REF 2021 as far as the impact agenda is concerned. It is, as he calls it, the only game in town, and we have been expected to write impact statements as part of UK research grant funding applications for a good number of years now. The unfairness of REF 2014 to spring impact on UK academics in the way it did, expecting us to document impact in a way we never knew we would have to show, has been mitigated in REF 2021 because we all know it's coming. This is cold comfort to some; we have been preparing impact case studies for our mock REF exercises since before the 2014 results, but there is no real way of knowing whether our planned impacts will

\footnotetext{
${ }^{2}$ Being Dutch, it's more like /' məret/ than /' məver/.
} 
have the expected results, garner good reports from users, or really demonstrate "change or benefit".

Another theme which appears throughout the book is the concern that people will stop doing the blue-skies research they are really interested in and enjoy (and may lead to measurable impact), changing direction in a much more instrumental way in order to do impactful research as outlined by the REF. My experience of this was being told by my REF lead to start working on accents of the UK and abandon my current research areas. I have resisted this, but I can see how others might feel they cannot. It is increasingly difficult to get a junior lectureship in the UK; those that do are under great pressure to produce the REF goods and show they are impactful. Recent movement towards teaching excellence, the TEF and teaching-intensive lectureships does not seem to have had much of an effect on the perceived supremacy of research and the need to show that one's useful deeds in society arise directly from research reported in publications. I am not saying that, as a senior academic, I can rest on my laurels - far from it, and I wouldn't want to anyway. What does concern me is that the pressure to perform, and the relatively low salaries available in UK higher education in comparison with industry, may deter otherwise brilliant early-career people from applying for lectureships in the first place. Either that or, having taken up a lectureship, they may burn out early on, leaving academia in order to take up industry posts which may be less stressful for more gain.

But back to the questions I asked at the start of this chapter: What is the point in academics and our research if not to contribute to society in an overt way? And shouldn't that contribution be demonstrable and quantifiable? Let us look at these questions in the context of the next round of assessments.

Coming from an applied linguistics and ELT background, I have always believed that research in our area will ultimately lead to better outcomes for language learners. That, if you like, is the point of applied linguists: it is applied, not (purely) theoretical. It has been possible to demonstrate that theories of language learning and acquisition have led to those better outcomes. It is quantifiable and demonstrable. As we are now used to our roles as potentially impactful beans waiting to be counted, and as we have had to plan our research funding applications much more carefully to include statements giving a convincing account of how our work will impact on society and bring about a positive effect, change or benefit, the future for REF 2021 impact case studies in applied linguistics, and linguistics in general, is looking bright. 
The accounts in some of the chapters in this book are very varied concerning readiness to show impact and the ease at which it was possible for REF 2014. In Chapter 5, for example, Lesley, Jim and Matthew show how difficult it was to evidence impact from a project which had, from the outset, aimed at being useful outside of academia, as their activities had been developed from theoretical research already done by others in the field of pragmatics; how far back does one go? Bas and Ellen, in Chapter 9, describe a research project which accidentally became useful outside of academia through the UK government's shake-up of grammar teaching in schools. They were able to show a direct connection between their own research on the ICE-GB corpus and their work educating school teachers in English grammar through the Englicious project, even though that had not been a stated outcome for the ICE-GB project. However, they point out that actual evidence that teachers are using Englicious in schools, and that this is improving grammar learning outcomes, is very difficult to provide in a REF submission, even though teachers might report that the workshops and supporting online activities are informative and inspiring.

For REF 2021, the period during which the research underpinning impact case studies must have been carried out is 1st January 2000 to 30th December 2020. This means there will still be projects in the earlier part of the period which were not planned as necessarily having impact (i.e., there was no impact statement in the grant submission), but many will have had the impact agenda in mind. On the surface, it looks like we are less likely to be in the position described in, e.g., Chapters 5 or 9. But is this really the case? The problems of being able to clearly evidence impact will not go away entirely, and it will be up to the subjective judgement of REF panellists to decide if it has been clearly evidenced or not.

REF 2021 is also looking at including impact from public engagement activity. As Lynne points out in Chapter 4, impact in this area can be difficult to assess. This difficulty has been noted in the September 2017 Hefce Consultation on the Second Research Excellence Framework document; those responding to the consultation asked for much clearer guidelines on this point ${ }^{3}$. The issue of being, like me, a general expert whose research is not directly related to the public engagement activity one gets involved in and, therefore, not a suitable impact case study, does

3 http://www.hefce.ac.uk/media/HEFCE,2014/Content/Pubs/Independentresearch/2017/REF,201702/REF_2017_02.p df 
not seem to have been addressed, and it really should be. All our knowledge and skills derived from being in a scholarly environment are potentially of interest to and impactful outside of academia but, unless you can pinpoint a research project of your own from which this knowledge has come, it is not worth anything to your university in a REF sense. This seems like madness. I am not the sum total of my research.

Another matter worth mentioning here is that almost all public engagement work academics get involved in is done for free, particularly for broadcast media companies and newspapers. The university may set you up with an interview, but no funds are provided for, e.g., travel expenses, either from the interviewer or the university, and my university for one certainly doesn't operate like an agent and ask for a fee. It's taken for granted that we academics are there to advise, like a live version of Wikipedia. And it's not always an easy road to navigate. David, Marie-José and Adrian (Chapter 8) give an example of the media getting hold of something and not checking sources correctly, with the result that their work was frequently mis-attributed. I've read newspaper articles where an academic has been interviewed on, e.g., accent change in the UK, and the journalist has turned the research findings to their own diversity-unfriendly political agenda in a way which is quite shocking. In that there is no material reward or REF recognition for this kind of work, and your message might be misreported and incorrectly attributed anyway, a question which might be asked is, why do it? I do it because I feel it is part of my role, as an expert and scholar, to add value to society where I can, be a reliable source on which the public and the media can draw, and try to give accurate information and an informed, balanced opinion in the face of the modern obsession with "fake news" and sensational reporting, whether or not this plays into the hands of some political agenda (thank you very much, Mr Gove). I also share Lynne's personality trait of enjoying the invitations, attention, and the opportunity to be an effective public educator. Let's face it: language is fascinating, and I want to talk about that with as many people as possible.

There is no doubt that the impact agenda is here to stay. Once introduced, these government initiatives are very difficult to shift and, to be completely honest, I think it is fair enough that universities which receive public funding should be demonstrating their worth outside of those perceived ivory towers. This comes through as a theme in the book; the authors are generally in favour of doing work which has useful applications in society, but they are critical of the way it is assessed by government bodies. What concerns me is that academics 
might now be pressed to plan their research in reverse, thinking first about what society needs, and then about how to go about doing research that aims to address and evidence solely that aim; the tail wagging the dog, if you will. This is not a bad thing, necessarily but - as we have seen in this book - ultimately, some of the most useful applications for society have arisen from people doing research because they wanted to answer a theoretical question, rather than directly address a societal need.

I am also concerned that the pressure to show impact and of being an impact case study takes academics away from the other main activity we are supposed to be engaged in and receive government and public funding for, i.e., teaching university students and facilitating their intellectual development. This alone can be a highly impactful activity, but - as it takes place in an academic setting - we are not permitted to evidence it through REF. Whether or not the TEF allows academics to evidence this impact is questionable ... and probably the subject for a different book.

\section{References}

Brumfit, C. J. and Johnson, K. (eds). (1979). The communicative approach to language teaching. Oxford: Oxford University Press.

Halliday, M. A. K. (1978). Language as social semiotic. Arnold: London.

Jones, D. (2011). Cambridge English Pronouncing Dictionary. 18th Edition, edited by Roach, P, Setter, J. \& Esling, J. Cambridge: Cambridge University Press.

Krashen, S. D. (1985). The input hypothesis: Issues and implications. Boston, MA: AddisonWesley Longman Ltd. 